Delft University of Technology

\title{
Roll-to-Roll Slot Die Coated Perovskite for Efficient Flexible Solar Cells
}

Galagan, Yulia; Di Giacomo, Francesco; Gorter, Harrie; Kirchner, Gerwin; de Vries, Ike; Andriessen, Ronn; Groen, Pim

DOI

10.1002/aenm.201801935

Publication date

2018

Document Version

Final published version

Published in

Advanced Energy Materials

\section{Citation (APA)}

Galagan, Y., Di Giacomo, F., Gorter, H., Kirchner, G., de Vries, I., Andriessen, R., \& Groen, P. (2018). Rollto-Roll Slot Die Coated Perovskite for Efficient Flexible Solar Cells. Advanced Energy Materials, [1801935]. https://doi.org/10.1002/aenm.201801935

\section{Important note}

To cite this publication, please use the final published version (if applicable).

Please check the document version above. 
Green Open Access added to TU Delft Institutional Repository 'You share, we take care!' - Taverne project

\section{https://www.openaccess.nl/en/you-share-we-take-care}

Otherwise as indicated in the copyright section: the publisher is the copyright holder of this work and the author uses the Dutch legislation to make this work public. 


\title{
Roll-to-Roll Slot Die Coated Perovskite for Efficient Flexible Solar Cells
}

\author{
Yulia Galagan,* Francesco Di Giacomo, Harrie Gorter, Gerwin Kirchner, Ike de Vries, \\ Ronn Andriessen, and Pim Groen
}

The feasibility of upscaling the perovskite solar cells technologies to high volume production using roll-to-roll (R2R) slot die coating is demonstrated in this study. Perovskite solar cells are produced by R2R slot die coating on flexible substrates with a width of $30 \mathrm{~cm}$ and the web speed of 3-5 $\mathrm{m} \mathrm{min}^{-1}$. R2R deposition of the electron transport layer and perovskite is performed at ambient atmosphere from nontoxic solvents compatible with industrial manufacturing. The average stabilized power conversion efficiency of the devices made on different areas of the foil is $12 \%$, with the best value of 13.5\%. The demonstrated achievement is an important milestone and a big solid step toward future commercialization of perovskite-based solar cells technologies.

\section{Introduction}

The rapid progress in the development of perovskite-based solar cells (PSCs) has been demonstrated in the last few years. ${ }^{[1-4]}$ Reaching power conversion efficiencies (PCE) of up to $23.3 \%$, PSCs compete with the efficiencies of $\mathrm{mc}-\mathrm{Si}$, copper indium gallium selenide solar cells (CIGS), and CdTe-based solar cells. With the very promising characteristics of strong solar spectrum absorption, tunable bandgap, and low nonradiative recombination, PSCs have the potential to approach (or even surpass) the record PCE values of c-Si-based solar cells in the near future. Although a lot of issues such as stability, toxicity, etc., are still to be addressed and solved before the commercialization of the PSC technologies, a development of large area industry-compatible technologies is already required at the current stage in order to speed up the progress in the perovskite field. Driven by these requirements, more and more studies are currently focused on upscaling the perovskite technologies..$^{[5-9]}$ Advanced achievements have been already demonstrated in the

Dr. Y. Galagan, Dr. F. Di Giacomo, H. Gorter, G. Kirchner, I. de Vries, Dr. R. Andriessen, Prof. P. Groen

TNO/Holst Centre-Solliance

High Tech Campus 21, 5656 AE, Eindhoven, The Netherlands

E-mail: yulia.galagan@tno.nl

Prof. P. Groen

Faculty of Aerospace Engineering

Delft University

Kluyverweg 1, 2629 HS Delft, The Netherlands

The ORCID identification number(s) for the author(s) of this article can be found under https://doi.org/10.1002/aenm.201801935.

DOI: 10.1002/aenm.201801935 area of large area perovskite solar cells and modules by using sheet-to-sheet (S2S) techniques. ${ }^{[10-14]}$ Blade coating is often employed as a scalable method for the manufacturing of PSC and has demonstrated PCE values of $19-20 \%$ on cell leve ${ }^{[15,16]}$ and PCE values of $15.3 \%$ and $14.6 \%$ for modules with aperture areas of 33.0 and $57.2 \mathrm{~cm}^{2}$, respectively. ${ }^{[16]}$ Monolithic perovskite modules with an active area of $70 \mathrm{~cm}^{2}$ and with a PCE of $10.74 \%$ were fabricated using scalable printing processes. ${ }^{[12]}$ S2S slot die coated solar cells on a glass substrate with the efficiency of $11.96 \%$ were demonstrated by Hwang et al. ${ }^{[11]}$ and $5 \times 5 \mathrm{~cm}^{2}$ modules with PCE of $10.6 \%$ were demonstrated by Cai et al. ${ }^{[17]}$ Slot-die coated perovskite-based photovoltaic (PV) modules of $168 \mathrm{~cm}^{2}$ with a PCE of $10 \%[18,19]$ and later the modules of $144 \mathrm{~cm}^{2}$ with a PCE of $14.5 \%$ were in a recent press release of Solliance. ${ }^{[20]}$

In order to allow the manufacturing of flexible PSCs for future high-volume production, roll-to-roll (R2R) processing technologies need to be developed. ${ }^{[21,22]}$ First attempts of R2R manufacturing have been demonstrated already by some research groups. ${ }^{[23-27]}$ A mini slot die coater built on a 3D printing platform allowed the manufacturing of flexible perovskite solar cells with up to $11.0 \%$ PCE. ${ }^{[25]}$ A blowing-assisted drop-casting on flexible R2R moving substrates results in perovskite solar cells with PCE of up to $11.16 \% .{ }^{[26]}$ However, future mass production of the perovskite solar cells requires the development of industry compatible large area deposition methods. The technology for R2R deposition of PSC requires optimization of several parameters simultaneously, namely: 1) proper solvent choice (viscosity, boiling point, toxicity, price, etc.); 2) fast crystallization kinetics (required by the high speed of the R2R deposition) preferably in ambient atmosphere; 3) layer uniformity over the large area; 4) PCE of the devices, etc. Hence, a dedicated optimization of the R2R drying and annealing conditions, which heavily contribute to the abovementioned issues, will be needed. The current study is the first successful example of large area R2R manufacturing of PSC in ambient condition using nontoxic solvents. The developed processes are compatible with industrial manufacturing on a plastic substrate. The stabilized efficiencies of the manufactured devices reached the record value of $13.5 \%$. Using prototype industrial processes and equipment with optimized in-line R2R coating, drying, and annealing, the results of this study will help in bringing the PSC technology one step closer to future commercialization. 


\section{Results and Discussion}

For R2R manufacturing, a planar n-i-p configuration of PSC has been selected with the following device architecture: polyethylene terephthalate (PET)/indium tin oxide (ITO) $/ \mathrm{SnO}_{2} /$ Perovskite/Spiro-OMeTAD/Au. Slot die coating of an aqueous solution of $\mathrm{SnO}_{2}$ on top of a commercial PET/ITO substrate results in a uniform transparent layer with a thickness of about $45 \mathrm{~nm}$. The R2R deposition of the perovskite layer requires very careful selection of the solvents and the perovskite precursor. A selection of industrial viable and acceptable solvents is described by us elsewhere. ${ }^{[28]}$ Typical solvents for the preparation of perovskite precursor are dimethyl formamide (DMF), $\mathrm{N}$-methylpyrrolidone (NMP), dimethyl sulfoxide (DMSO), and $\gamma$-butyrolactone (GBL). Despite the high PCEs obtained in perovskite devices using DMF and NMP, this solvent is not suitable for the industrial mass production due to its toxicity. Recently a mixture of methylamine and acetonitrile was proposed as an alternative nonhazardous mixture for $\mathrm{CH}_{3} \mathrm{NH}_{3} \mathrm{PbI}_{3}$ precursor deposition. ${ }^{[29]}$ However, the very low boiling point and high flammability of this solvent system hamper its industrial application. A mixture GBL with $\mathrm{DMSO}^{[30]}$ or different alcohols ${ }^{[31]}$ can be considered as a nonhazardous solvent system. However, GBL is classified as a psychoactive drug, and due to its legal status, the industrial use of this solvent is very limited. The last in the list of known solvents for perovskite precursors is DMSO. This solvent is widely used in industry and is one of the few dipolar aprotic solvents which does not have any legislation flags required additional attention for usage in the industrial processes. ${ }^{[32]}$ DMSO is not classified as a hazardous solvent. Due to easy penetration to the skin, sometimes this solvent is considered as a material with some safety concerns. However, the safe processes using DMSO are already industrially established and can be successfully adapted for the manufacturing of perovskites. Therefore, DMSO is a suitable nonhazardous solvent which can be used for industrial up-scalable manufacturing of perovskite solar cells.

However, owing to the very high surface energy and high boiling point of DMSO, a lot of macro and microscopic dewettings occur in the wet layer of the precursor, resulting in nonuniform perovskite layer over the large area after the drying, as shown in Figure S1a (Supporting Information). In addition to uniformity, a perovskite layer deposited from pure DMSO characterizes by very small dimension of the crystals, ${ }^{[28]}$ which negatively affects the final performance of the devices. ${ }^{[28,33]}$ Adding a cosolvent (2-butoxyethanol, 2BE) not only reduces the surface tension, which leads to better wettability and the formation of uniform layer (Figure S1b, Supporting Information), but also can accelerate the perovskite crystallization process, resulting in the formation of larger crystals. ${ }^{[28,34]}$ The change in the surface tension of DMSO with adding 2BE is shown in Figure S2 (Supporting Information). Adding $10 \%$ of $2 \mathrm{BE}$ reduced the surface tension of DMSO from 42.4 to $38.2 \mathrm{mN} \mathrm{m}^{-1}$. A further decrease in the surface tension is possible by adding more cosolvent. But solubility of the precursor materials, e.g., $\mathrm{PbI}_{2}$, is limited in $2 \mathrm{BE}$, and this negatively affects the perovskite layer formation. Thus, the optimal concentration of $2 \mathrm{BE}$ was identified as 10 vol\%. To better understand the effect of a cosolvent and evaluate the nonhazardous solvent mixture of DMSO/2BE, the reference devices were manufactured on glass substrates the procedure for manufacturing of spin coated reference devices is described in the Supporting Information). The results reveal (see Figure S3, Supporting Information) that the performance of the devices manufacturing using a DMSO/2BE solvent mixture is slightly lower than the performance of the devices manufactured using DMF, but higher than that of the devices manufactured using DMSO as a mono solvent.

The solvent composition is not the only parameter influencing the crystallization kinetics of the perovskite. Also, the crystals size in the R2R coated layer strongly depends on the drying and annealing conditions and the particular precursor composition. The R2R experiments were executed for realizing a methylammonium (MA) lead iodide $\left(\mathrm{CH}_{3} \mathrm{NH}_{3} \mathrm{PbI}_{3}\right)$ and mixed cations and halides $\left(\mathrm{Cs}_{0.15} \mathrm{FA}_{0.85} \mathrm{PbI}_{3-x} \mathrm{Br}_{x}\right)$ perovskite compositions. The R2R coating line used in this study ${ }^{[35]}$ employs a novel concept that allows a transport of the carrier substrate through two sequential coating stations and drying ovens, without ever contacting the top surface of the coatings, thereby preventing a surface contamination. The R2R coating line used in this study is shown in Figure S4 (Supporting Information). The $20 \mathrm{~m}$ long R2R dryer system used in this study is subdivided into the sections of $1 \mathrm{~m}$ long. The temperature in each section can be set individually. ${ }^{[35]}$ The design of the dryer allows varieties of drying settings with fast and slow ramping a temperature. Here we report two drying settings which have the most of interest: i) the settings where the temperature was gradually increased, reaching the maximum of $140^{\circ} \mathrm{C}$ after some time of drying, and ii) the setting where the maximum temperature was reached already from the beginning of the drying. Perovskite layer was coated and dried with the speed of $3 \mathrm{~m} \mathrm{~min}^{-1}$, which results in a total annealing time of $7 \mathrm{~min}$ using the drying system of the $\mathrm{R} 2 \mathrm{R}$ line. The gradual increase of the temperature using settings i) occurs in the first three sections of the driers, reaching $140{ }^{\circ} \mathrm{C}$ after $1 \mathrm{~min}$ of drying. First results in $\mathrm{CH}_{3} \mathrm{NH}_{3} \mathrm{PbI}_{3}$ deposition produced from $\mathrm{PbI}_{2}$ and methylammonium iodide (MAI) precursors in DMSO/2BE and dried with a gradual temperature ramping, leading to the formation of needle-like perovskite crystals (see Figure 1a). Formation of needle-like structures in $\mathrm{CH}_{3} \mathrm{NH}_{3} \mathrm{PbI}_{3}$ is widely described in a literature. ${ }^{[36,37]}$ The theory behind the formation of needle-like structures is that a complex adduct $\mathrm{MAI} \cdot \mathrm{PbI}_{2} \cdot x \mathrm{DMSO}$ present in a precursor solution serves as the heterogeneous nucleation sites and can assemble into bulk structures within the solution because of the strong van der Waals bonding. ${ }^{[36]}$ Resulting crystals, described in literature, typically have needle-like structures like those obtained in the R2R experiment. Modifying the drying settings to faster temperature ramp-up, where the solvent evaporation was accelerated which speeds-up the crystallization process, results in the formation of the plate-like crystals (Figure 1b). This effect is similar to so-called "hot-casting" deposition process, ${ }^{[16,37,38]}$ and the similarity should come from the fact that the crystals have a rather fast growth when the solvent is still present due to the quick rise in temperature, resulting in a semi-wet growth that allows fabricating bigger crystals. However, despite the appearance of plate-like crystals in the $\mathrm{CH}_{3} \mathrm{NH}_{3} \mathrm{PbI}_{3}$ layer, a substantial number of needle-like crystals were still present.

To further improve the quality of the perovskite layer and its crystal structures, the following R2R experiments were focused 


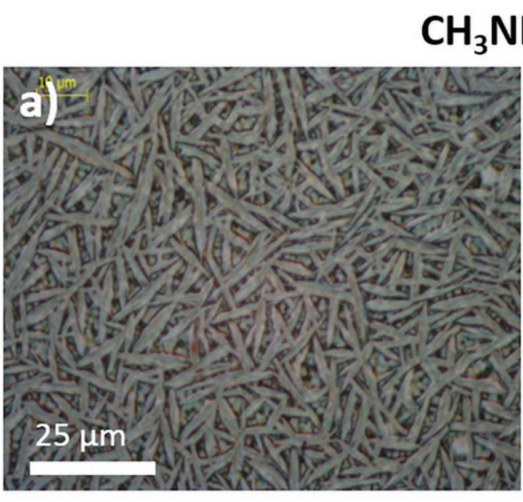

\section{$\mathrm{CH}_{3} \mathrm{NH}_{3} \mathrm{Pbl}_{3}$}
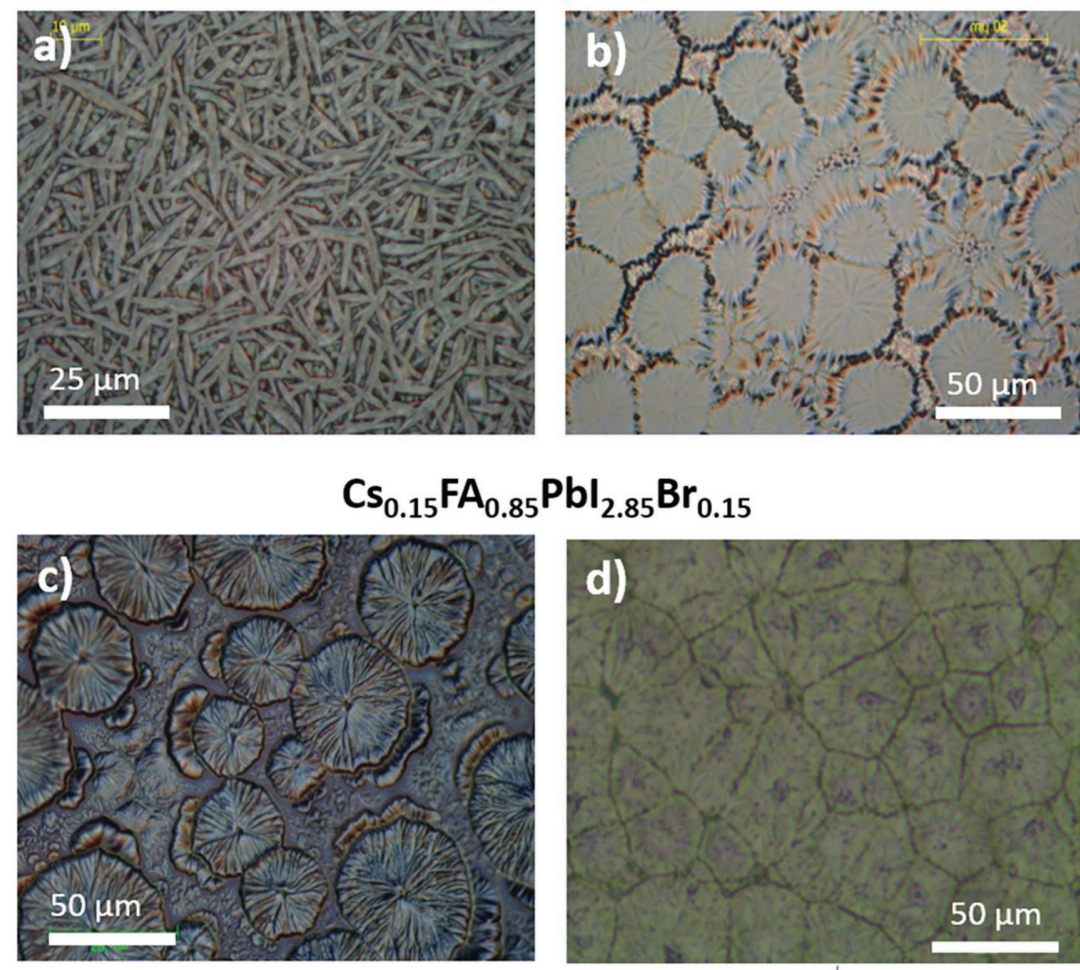

$\mathrm{Pbl}_{2.85} \mathrm{Br}_{0.15}$
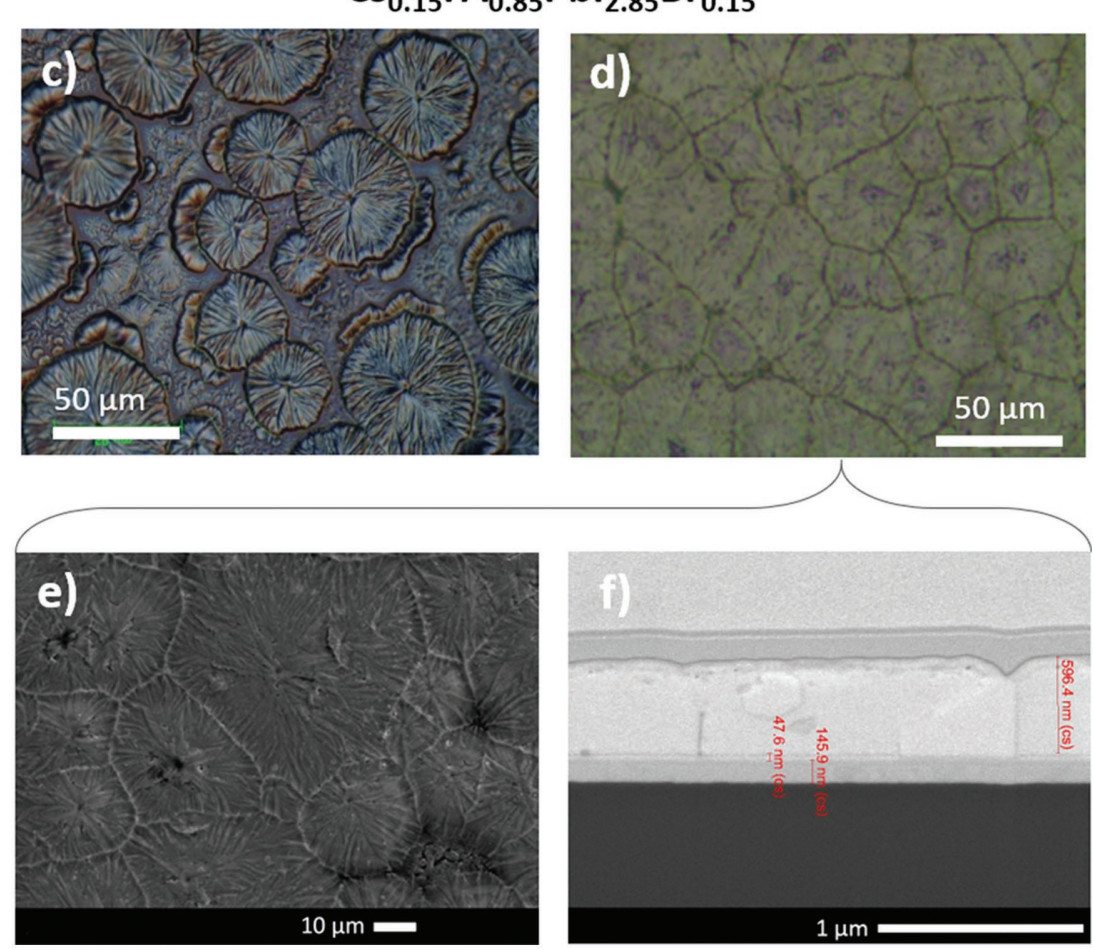

Figure 1. The microstructures (optical microscope) of the perovskite layers: a) and b) $\mathrm{CH}_{3} \mathrm{NH}_{3} \mathrm{Pbl}_{3}$ layer dried at $140{ }^{\circ} \mathrm{C}$ with slow and fast temperature ramping, respectively. c) and d) $\mathrm{Cs}_{0.15} \mathrm{FA}_{0.85} \mathrm{Pbl}_{2.85} \mathrm{Br}_{0.15}$ layer dried with slow and fast temperature ramping, respectively. e) The SEM image of this perovskite layer presented in (d). f) Cross-sectional FIB-SEM image of $\mathrm{SnO}_{2}$ and perovskite layers R2R coated on PET/ITO substrates, the perovskite layer $\mathrm{Cs}_{0.15} \mathrm{FA}_{0.85}$ $\mathrm{Pbl}_{2.85} \mathrm{Br}_{0.15}$ dried with fast temperature ramping (corresponding to the images (d) and (e)). obviously is almost never really considered at a lab scale processing. Dual A-cation composition does not contain methyl ammonium, the usage of which can be critical for mass production. Investigating the gas phases produced during heating up the precursor and/or perovskite at high temperatures, the researchers from SPECIFIC detected the formation of methyl iodide $\left(\mathrm{CH}_{3} \mathrm{I}\right)$ as a product of the decomposition of $\mathrm{CH}_{3} \mathrm{NH}_{3} \mathrm{I}$ and $\mathrm{CH}_{3} \mathrm{NH}_{3} \mathrm{PbI}_{3} \cdot{ }^{[4]}$ Due to its hazardous nature, the presence of $\mathrm{CH}_{3} \mathrm{I}$ is not acceptable in mass production processes. Although the detection of $\mathrm{CH}_{3} \mathrm{I}$ occurs only at the temperatures above $200{ }^{\circ} \mathrm{C}$, still, the potential risk for humans and the environment must be completely omitted during the manufacturing and the usage of the PSC. Thus, the usage of MA-free composition for manufacturing PSC is supported and highly desired for a future large-scale mass production.

A similar solvent composition and drying settings, used for $\mathrm{CH}_{3} \mathrm{NH}_{3} \mathrm{PbI}_{3}$, were applied in the manufacturing of a mixed-cation mixed-halide perovskite $\left(\mathrm{Cs}_{0.15} \mathrm{FA}_{0.85} \mathrm{PbI}_{2.85}\right.$ $\left.\mathrm{Br}_{0.15}\right)$. As expected, the crystallization pattern of the R2R manufactured $\mathrm{Cs}_{0.15} \mathrm{FA}_{0.85}$ $\mathrm{PbI}_{2.85} \mathrm{Br}_{0.15}$ layer was different from the previously described $\mathrm{CH}_{3} \mathrm{NH}_{3} \mathrm{PbI}_{3}$ layers, as shown in Figure 1c,d. The microstructures of the layers with both slow and fast temperature ramp-up lead to the formation of plate-like crystals, and there is no tendency to the formation of needle-like crystals which observed in the $\mathrm{CH}_{3} \mathrm{NH}_{3} \mathrm{PbI}_{3}$ composition. Moreover, it seems that a fast temperature ramp-up has a positive effect on the crystallization process: the crystal grains are densely packed forming uniform layer. The scanning electron microscope (SEM) image of this perovskite layer is shown in Figure 1e. The uniformity of the layer over large area was checked using optical microscope. The images taken with the interval of $\approx 1.5 \mathrm{~cm}$ along the entire width of the substrate (perpendicular to the coating direction) demonon the preparation of mixed-cation mixed-halide perovskite layers: $\mathrm{Cs}_{0.15} \mathrm{FA}_{0.85} \mathrm{PbI}_{2.85} \mathrm{Br}_{0.15}$, containing cesium (Cs) and formamidinium $\left(\mathrm{CH}_{3}\left(\mathrm{NH}_{2}\right)^{2+}, \mathrm{FA}\right)$ cations. A lot of reports ${ }^{[39-42]}$ point on the enhanced crystal formation using mixed A-cation combinations such as MA, FA, and Cs. According to Rehman et al., ${ }^{[41]}$ the mixed-cation mixed-halide perovskites $\mathrm{Cs}_{\gamma} \mathrm{FA}_{(1-\gamma)} \mathrm{Pb}\left(\mathrm{Br}_{x} \mathrm{I}_{1-\mathrm{x}}\right)_{3}$ could be crystallized at much higher temperatures than previously reported hybrid perovskites, which lead to materials with high levels of crystallinity. This suggests the usage of mixed-cation mixed-halide perovskites in $\mathrm{R} 2 \mathrm{R}$ experiments instead of $\mathrm{CH}_{3} \mathrm{NH}_{3} \mathrm{PbI}_{3}$. Furthermore, usage of the dual A-cation (CsFA) based precursor composition has an additional advantage for a large-scale R2R processing, which strate the high uniformity of the coated layer (see Figure S5, Supporting Information). The cross-section of two R2R coated layers on ITO substrate is presented in Figure 1f, confirming that the thicknesses of the obtained layers were in the ranges of $146 \mathrm{~nm}$ ITO, $47 \mathrm{~nm} \mathrm{SnO}_{2}$, and $600 \mathrm{~nm}$ perovskite layer. The X-ray diffraction (XRD) analysis and UV-Vis absorption of optimized coatings, shown in Figure 2, confirm full conversion of the precursor to perovskite phase.

To further evaluate the quality of the $\mathrm{R} 2 \mathrm{R}$ processed perovskite layer individual PSC devices were manufactured using $\mathrm{Cs}_{0.15} \mathrm{FA}_{0.85} \mathrm{PbI}_{2.85} \mathrm{Br}_{0.15}$ perovskite dried with the fast temperature ramping, corresponding to the layer shown in Figure $1 \mathrm{~d}-\mathrm{f}$. In this experiment, two layers $\left(\mathrm{SnO}_{2}\right.$ and perovskite) 

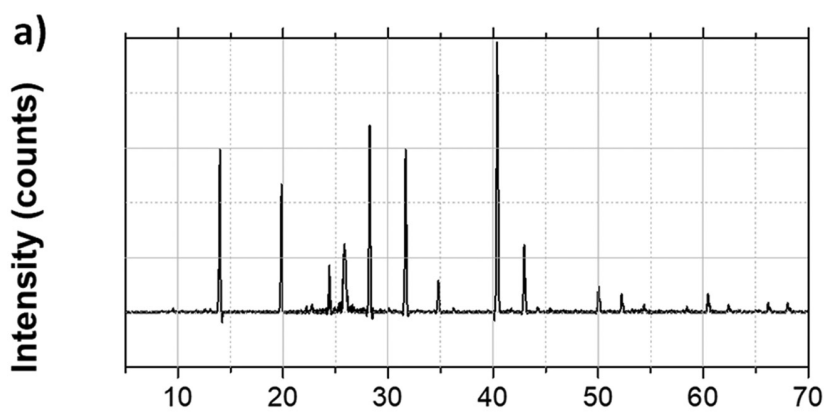

2Theta $\left({ }^{\circ}\right)$

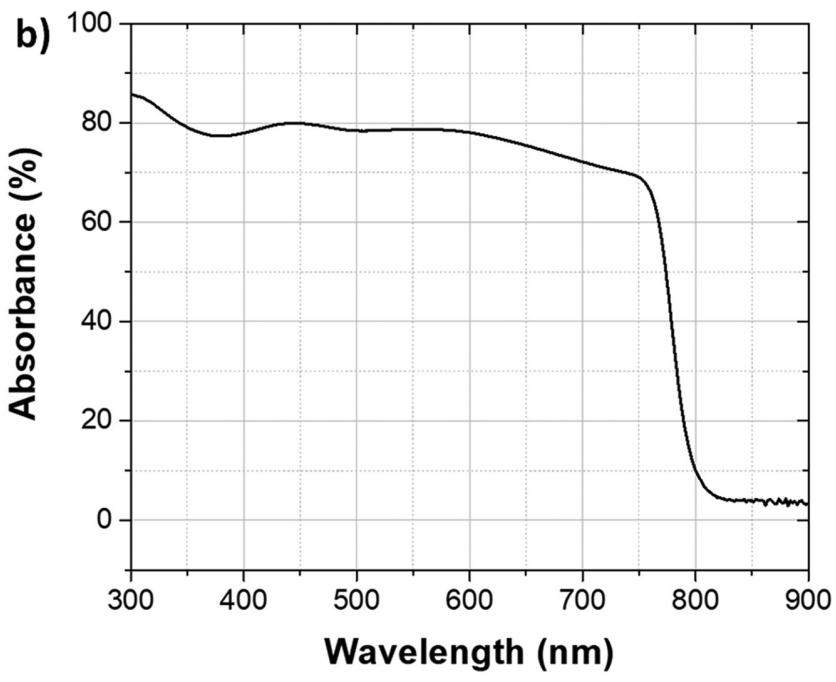

Figure 2. a) XRD pattern and b) UV-vis absorbance of R2R coated perovskite layer $\mathrm{Cs}_{0.15} \mathrm{FA}_{0.85} \mathrm{Pbl}_{2.85} \mathrm{Br}_{0.15}$.

were produced by the R2R slot die coating in the ambient atmosphere (RH $60 \%$ and the temperature $25^{\circ} \mathrm{C}$ ) on a PET/ITO substrate. Subsequently, pieces of the foil (see Figure 3) were cut out from the produced PET/ITO/ $\mathrm{SnO}_{2} /$ Perovskite roll and PSC devices were completed either by spin coating hole-transport layer (HTL) (Spiro-OMeTAD) with the following thermal evaporation of the $\mathrm{Au}$ contacts (an example of the devices is shown in Figure 3). In approximately three months after finishing the experiment, another R2R experiment took a place, where $\mathrm{SnO}_{2}$ and Perovskite were deposited with the identical R2R settings. But different deposition method was applied for SpiroOMeTAD. In the second experiment Spiro-OMeTAD was S2S slot die coated. The S2S deposition process of Spiro-OMeTAD is described by us elsewhere. ${ }^{[19]}$ Both the experiments (see details of the Spiro-OMeTAD deposition in the Experimental Section) show very comparable results, pointing on a reproducibility of the developed R2R technologies. The JV curves of the best performing device (the devices from the second experiment) having an active area of $0.09 \mathrm{~cm}^{2}$ are shown in Figure 4a. The reverse JV scans of the best performing devices demonstrate PCE values as high as $15.2 \%$. The JV scans were performed with a scan rate of $300 \mathrm{mV} \mathrm{s}^{-1}$. Performing the measurements with relatively high scan rate results in substantial hysteresis in the JV curves measured under forward and reverse bias (observed also for the spin-coated equivalent). To determine a more reliable efficiency of the devices, a maximum power point tracking was performed for $150 \mathrm{~s}$, as shown in Figure 4b. Thus, a stabilized efficiency of up to $13.5 \%$ was measured, which is the highest value reported so far for R2R processed perovskite solar cells and is a remarkable PCE among all the others flexible PSCs reported so far. ${ }^{[21]}$ To demonstrate a statistical distribution in the PCE values over the large coated area, more individual devices were manufactured where the pieces of the foil were taken from the different areas of the roll. An average stabilized efficiency out of two experiments was 12\%. Figure 5 illustrates the distribution of the individual device parameters measured under both reverse and forward scans in two experiments.

The perovskite thickness of $600 \mathrm{~nm}$ appears to be optimal for the uniform layer formation and provides best PCEs. The thinner layer $(\approx 400 \mathrm{~nm})$ results in a high number of pinholes in the perovskite layer, as shown in Figure S6a (Supporting Information). On the contrary, although the thicker layer is highly dense (see Figure S6b, Supporting Information), high thickness of perovskite layer $(900 \mathrm{~nm})$ negatively affects the device performance (see Figure S7, Supporting Information) leading to lower efficiency and worse reproducibility of the results. A comparison between the PCEs of R2R manufactured devices and the PCEs of the devices produced by spin coating

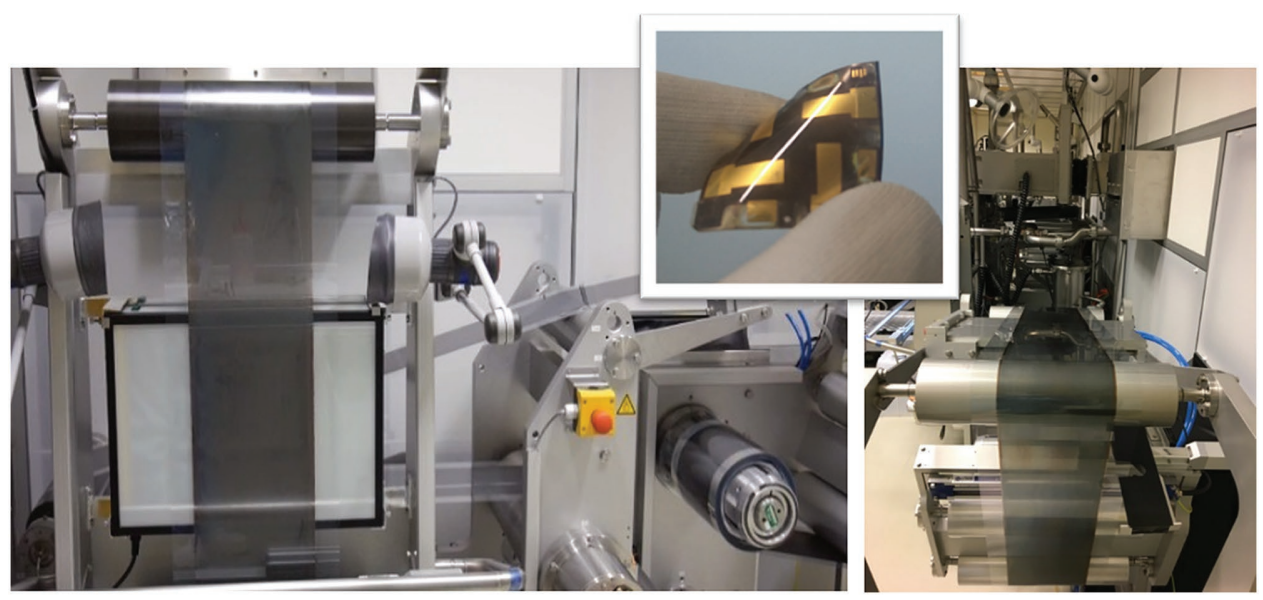

Figure 3. Photograph images of the roll-to-roll coated perovskite layer $\left(\mathrm{Cs}_{0.15} \mathrm{FA}_{0.85} \mathrm{Pbl}_{2.85} \mathrm{Br}_{0.15}\right)$ and an example of the manufactured flexible devices. 

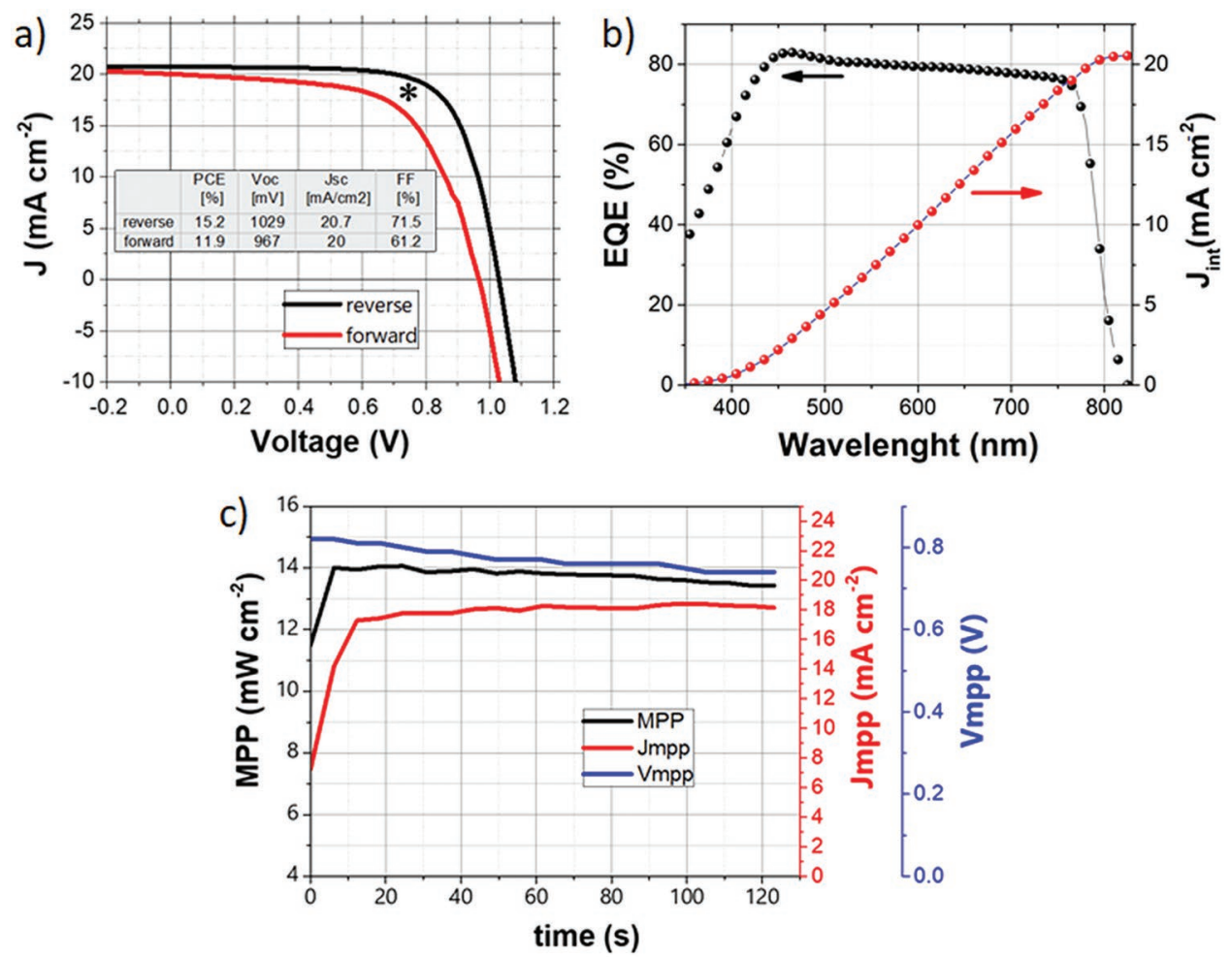

Figure 4. a) JV curves of the best-performing cell measured under forward and reverse scan. b) External quantum efficiency (EQE) and integrated current density in that devices. c) Maximum-power-point tracking of the best devices, measured under the bias $V_{M P p}$. A star mark (*) at figure (a) is stabilized MPP tracked efficiency defined at figure (c). The best performing device is the devices from second experiment with slot die coated SpiroOMeTAD, it corresponds to the red star in Figure 5 at PCE plot.

on glass substrates is presented in the Supporting Information. Notably, the identical stack produced from the perovskite precursor dissolved in DMF on glass substrates using spin coating results in an average stabilized efficiency of $15.8 \%$. While using a DMSO/2BE solvent system for manufacturing of perovskite layer results in an average stabilized PCE of $13.5 \%$ (see Figure S3, Supporting Information). This is just slightly higher of the average PCEs obtained on a flexible substrate using R2R slot die coating. This difference can be addressed to the difference in the sheet resistance of the ITO electrode used in manufacturing of glass-based and flexible substrates. This statement was confirmed by measuring flexible R2R manufacturing devices with a smaller shadow mask, which results in the higher PCE of the devices. Thus, measuring the devices with the mask of $0.04 \mathrm{~cm}^{2}$ results in the stabilized PCEs up to $14.5 \%$. Finally, flexibility test with R2R manufactured devices using a bending radius of $10 \mathrm{~mm}$ reveals that after 1000 bending cycles the stabilized maximum power point (MPP) tracked efficiency remains unchanged (see Figure S6, Supporting Information). The efficiency of these devices also does not change after $1000 \mathrm{~h}$ of storage in a nitrogen atmosphere.

\section{Conclusion}

This study is the first public demonstration with a proven feasibility for the R2R slot die coating of the electron transport layer (ETL) and the perovskite layer over the large area on flexible substrates with a width of $30 \mathrm{~cm}$. The developed deposition processes allowed a manufacturing of individual perovskite photovoltaic devices with the stabilized PCE of up to $13.5 \%$. The coatings of ETL and perovskite are performed under ambient atmospheric conditions using industrially accepted solvents. Simultaneously, a R2R coating and high speed allowed the manufacturing of several hundred meters of the films with two coated layers. Although complete R2R manufacturing of the devices still needs to be elaborated (HTL and top electrode), the current intermediate research results are a proof of the concept and at the same time a first solid step toward future manufacturing and commercialization of the perovskite-based PV technology. The video file demonstrating the R2R slot die coating and drying process of the perovskite layer on the Solliance $\mathrm{R} 2 \mathrm{R}$ coating line is available in the Supporting Information.

\section{Experimental Section}

Tin oxide $\left(\mathrm{SnO}_{2}\right)$ colloidal dispersion (15 wt\%) purchased from Alfa Aesar was diluted by water and 1-butanol, in order to get $1.2 \mathrm{wt} \%$ solution. The volume fraction of 1-butanol was 10 vol\%. R2R slot die coating of $\mathrm{SnO}_{2}$ solution was performed on the PET/ITO substrate (Eastman, $40 \mathrm{Ohm} \mathrm{sq}^{-1}$ ) with the speed of $5 \mathrm{~m} \mathrm{~min}^{-1}$ and dried with the same speed at $140{ }^{\circ} \mathrm{C}$. Lead iodide $\left(\mathrm{Pbl}_{2}\right)$ (Sigma-Aldrich, $99 \%$ ) and MAI (Dyesol, 99\%) at a molar ratio 1.05:1 were dissolved in the DMSO/2BE solvent system and stirred at least $60 \mathrm{~min}$ before use. The DMSO/2BE solvent system contained $10 \%$ of $2 \mathrm{BE}$. The precursor for mixed-cation mixed-halide system contained stoichiometric molar ratio of cesium iodide (Csl) (Sigma-Aldrich), formamidine iodide (Fal) (Dyesol) $\mathrm{Pbl}_{2}$, 

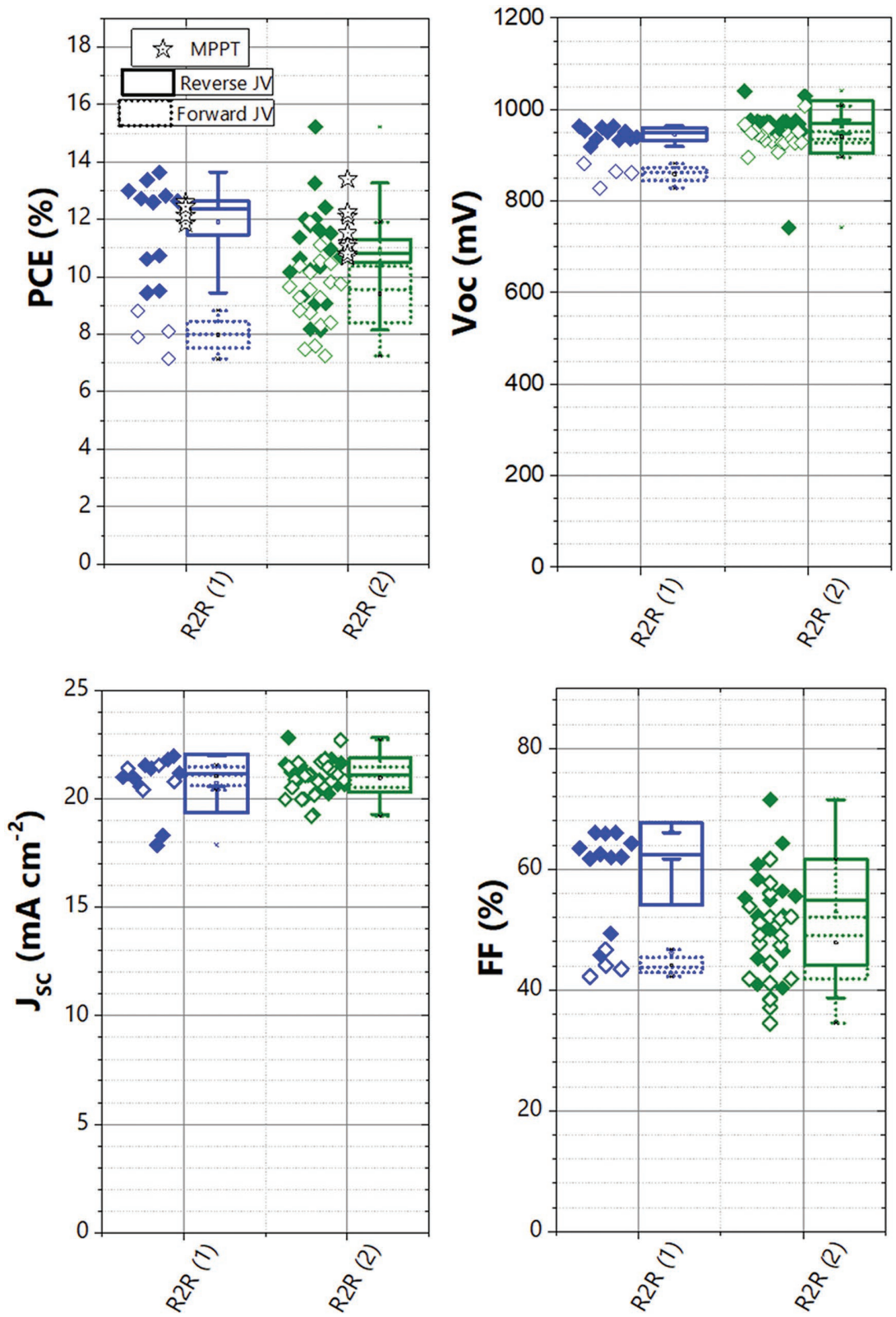

Figure 5. Statistical distribution of PCE, $J_{\mathrm{sc}}, \mathrm{FF}$, and $V_{\mathrm{oc}}$ of the devices measured under forward and reverse scans in two individual R2R experiments. Red star at the PCE graph corresponds to the device presented in Figure 4. hole transporting layer. S2S slot die coating was performed inside of the glove-box using nTact Coating System nRad 1. The Spiro-OMeTAD solution used for spin coating was diluted to the concentration of $30 \mathrm{mg} \mathrm{mL}^{-1}$. The deposition of Spiro-OMeTAD resulted in the dry layer of about 200-250 nm, similar to those obtained using a spin coating. The complete Spiro-OMeTAD oxygen doping was attained by exposing the substrates to air under the controlled humidity $(\mathrm{RH}=48 \%)$. Subsequently, the substrates were transferred to the thermal evaporator under the pressure of $1.0 \times 10^{-6}$ mbar, where a $100 \mathrm{~nm}$ of $\mathrm{Au}$ back electrode was deposited on top of the Spiro-OMeTAD film. However, because the ITO electrode was not patterned, an insulating material $\mathrm{SiO}_{x}$ was e-beam evaporated (Cryofox Scotty, rate $0.1 \mathrm{~nm} \mathrm{~s}^{-1}$ ) with a shadow mask under the Au contact points, in order to prevent shunting of the devices during the measurements. Then, the Au electrodes were evaporated with shadow mask to determining the active area of the device, which is $0.16 \mathrm{~cm}^{2}$. Finally, the devices were measured with the illumination mask of $0.09 \mathrm{~cm}^{2}$. Due to nonoptimized methodology for the manufacturing of the flexible device on the nonpatterned ITO substrates, some devices were shunted. Shunted devices were removed from the statistical calculations presented in Figure 4 . The manufacturing yields in both R2R experiments were $\approx 75 \%$ and $69 \%$, respectively.

The J-V measurements were carried out under the simulated AM $1.5 \mathrm{G}$ sunlight condition, by using a tungsten-halogen lamp $\left(\approx 100 \mathrm{~mW} \mathrm{~cm}{ }^{-2}\right)$ and a Keithley 2400 source meter. XRD measurements were carried out in a Bragg-Brentano configuration with a Panalytical Empyrean using Cu K(alpha) radiation. UV-visible absorption spectra were measured with a Agilent Cary 5000 spectrophotometer. The top view SEM pictures were acquired with a Jeol JSM-6010LA IntouchScope, while cross-section images were acquired after a focused ion beam (FIB) milling.

\section{Supporting Information}

Supporting Information is available from the Wiley Online Library or from the author. and lead bromide $\left(\mathrm{PbBr}_{2}\right)(\mathrm{TCl})$, in order to fabricate $\mathrm{Cs}_{0.15} \mathrm{FA}_{0.85} \mathrm{Pbl}_{2-x} \mathrm{Br}_{x}$ perovskite phase. A R2R coating and drying of precursor solution was performed at the speed of $3-5 \mathrm{~m} \mathrm{~min}^{-1}$. The drying settings are presented in the results and discussion.

Two layers $\left(\mathrm{SnO}_{2}\right.$ and perovskite) were R2R coated on a PET/ITO substrate, then small pieces of the foil were cut out from the roll and PSC devices were completed by either spin coating (experiment 1) or S2S slot die coating (experiment 2) of Spiro-OMeTAD and thermal evaporation of $\mathrm{Au}$ contacts. For spin coating, the Spiro-OMeTAD solution $(80 \mathrm{mg}$ of Spiro-O-MeTAD (Lumtec), $28 \mu \mathrm{L}$ of 4-tert-butylpyridine, $17.5 \mu \mathrm{L}$ of a $520 \mathrm{mg} \mathrm{mL}^{-1} \mathrm{LiN}\left(\mathrm{CF}_{3} \mathrm{SO}_{2}\right)_{2} \mathrm{~N}$ solution in acetonitrile, and $20 \mu \mathrm{L}$ of a $500 \mathrm{mg} \mathrm{mL}$ FK209 cobalt salt in acetonitrile were added to $1 \mathrm{~mL}$ of chlorobenzene) was spun at $2000 \mathrm{rpm}$ for $60 \mathrm{~s}$ onto the perovskite film and resulted in the formation of a $200 \mathrm{~nm}$ thick

\section{Acknowledgements}

This work was supported by Solliance, a partnership of R\&D organizations from the Netherlands, Belgium, and Germany working in thin film photovoltaic solar energy. This work is part of the research programme CLEARPV, grant M-ERA.NET $2017 \mathrm{CW}$ with project number 732.017.105, which is (partly) financed by the Netherlands Organisation for Scientific Research (NWO).

\section{Conflict of Interest}

The authors declare no conflict of interest. 


\section{Keywords}

flexible substrates, nonhazardous solvents, perovskite solar cells, roll-to-roll, slot-die coating

Received: June 22, 2018

Revised: September 11, 2018

Published online: October 8, 2018

[1] C. Zuo, H. J. Bolink, H. Han, J. Huang, D. Cahen, L. Ding, Adv. Sci. 2016, 3, 1500324.

[2] N.-G. Park, Nano Convergence 2016, 3, 1.

[3] N.-G. Park, M. Grätzel, T. Miyasaka, K. Zhu, K. Emery, Nat. Energy 2016, 1, 16152.

[4] J.-P. Correa-Baena, A. Abate, M. Saliba, W. Tress, T. Jesper Jacobsson, M. Gratzel, A. Hagfeldt, Energy Environ. Sci. 2017, 10, 710.

[5] S. Razza, S. Castro-Hermosa, A. Di Carlo, T. M. Brown, APL Mater. 2016, 4, 091508.

[6] T. M. Schmidt, T. T. Larsen-Olsen, J. E. Carlé, D. Angmo, F. C. Krebs, Adv. Energy Mater. 2015, 5, 1500569.

[7] Y. Galagan, E. W. C. Coenen, W. J. H. Verhees, R. Andriessen, J. Mater. Chem. A 2016, 4, 5700.

[8] L. Rakocevic, R. Gehlhaar, T. Merckx, W. Qiu, U. W. Paetzold, H. Fledderus, J. Poortmans, IEEE J. Photovoltaics 2017, 7, 404.

[9] W. Qiu, T. Merckx, M. Jaysankar, C. Masse de la Huerta, L. Rakocevic, W. Zhang, U. W. Paetzold, R. Gehlhaar, L. Froyen, J. Poortmans, D. Cheyns, H. J. Snaith, P. Heremans, Energy Environ. Sci. 2016, 9, 484

[10] L.-L. Gao, C.-X. Li, C.-J. Li, G.-J. Yang, J. Mater. Chem. A 2017, 5, 1548.

[11] K. Hwang, Y.-S. Jung, Y.-J. Heo, F. H. Scholes, S. E. Watkins, J. Subbiah, D. J. Jones, D.-Y. Kim, D. Vak, Adv. Mater. 2015, 27, 1241.

[12] A. Priyadarshi, L. J. Haur, P. Murray, D. Fu, S. Kulkarni, G. Xing, T. C. Sum, N. Mathews, S. G. Mhaisalkar, Energy Environ. Sci. 2016, 9, 3687.

[13] G. Cotella, J. Baker, D. Worsley, F. De Rossi, C. Pleydell-Pearce, M. Carnie, T. Watson, Sol. Energy Mater. Sol. Cells 2017, 159, 362.

[14] J. G. Tait, S. Manghooli, W. Qiu, L. Rakocevic, L. Kootstra, M. Jaysankar, C. A. Masse de la Huerta, U. W. Paetzold, R. Gehlhaar, D. Cheyns, P. Heremans, J. Poortmans, J. Mater. Chem. A 2016, 4, 3792.

[15] T. Shi, D. Yehao, Z. Xiaopeng, B. Yang, F. Yanjun, D. Qingfeng, W. Haotong, H. Jinsong, Adv. Energy Mater. 2017, 7, 1700302.

[16] Y. Deng, X. Zheng, Y. Bai, Q. Wang, J. Zhao, J. Huang, Nat. Energy 2018, 3, 560 .

[17] L. Cai, L. Liang, J. Wu, B. Ding, L. Gao, B. Fan, J. Semicond. 2017, 38, 014006.

[18] https://solliance.eu/solliance-realizes-a-first-up-scaled-perovskitebased-pv-module-with-10-efficiency/ (accessed: 2017).

[19] F. Di Giacomo, S. Shanmugam, H. Fledderus, B. J. Bruijnaers, W. J. H. Verhees, M. S. Dorenkamper, S. C. Veenstra, W. Qiu, R. Gehlhaar, T. Merckx, T. Aernouts, R. Andriessen, Y. Galagan, Sol. Energy Mater. Sol. Cells 2018, 181, 53.

[20] https://solliance.eu/solliance-sets-14-5-cell-performance-record-onlarge-perovskite-modules/ (accessed: 2018).
[21] F. Di Giacomo, A. Fakharuddin, R. Jose, T. M. Brown, Energy Environ. Sci. 2016, 9, 3007.

[22] A. Robert, G. Yulia, G. Pim, Adv. Eng. Mater. 2018, 20, 1701190.

[23] Q. Hu, H. Wu, J. Sun, D. Yan, Y. Gao, J. Yang, Nanoscale 2016, 8, 5350.

[24] L. H. Rossander, T. T. Larsen-Olsen, H. F. Dam, T. M. Schmidt, M. Corazza, K. Norrman, I. Rajkovic, J. W. Andreasen, F. C. Krebs, CrystEngComm 2016, 18, 5083.

[25] Y.-J. Heo, J.-E. Kim, H. Weerasinghe, D. Angmo, T. Qin, K. Sears, K. Hwang, Y.-S. Jung, J. Subbiah, D. J. Jones, M. Gao, D.-Y. Kim, D. Vak, Nano Energy 2017, 41, 443.

[26] C. Zuo, D. Vak, D. Angmo, L. Ding, M. Gao, Nano Energy 2018, 46, 185.

[27] J.-E. Kim, Y.-S. Jung, Y.-J. Heo, K. Hwang, T. Qin, D.-Y. Kim, D. Vak, Sol. Energy Mater. Sol. Cells 2018, 179, 80.

[28] J. Wang, F. Di Giacomo, J. Brüls, H. Gorter, I. Katsouras, P. Groen, R. A. J. Janssen, R. Andriessen, Y. Galagan, Sol. RRL 2017, 1, 1700091.

[29] N. K. Noel, S. N. Habisreutinger, B. Wenger, M. T. Klug, M. T. Horantner, M. B. Johnston, R. J. Nicholas, D. T. Moore, H. J. Snaith, Energy Environ. Sci. 2017, 10, 145.

[30] Y. Zhao, K. Zhu, J. Phys. Chem. Lett. 2014, 5, 4175.

[31] K. L. Gardner, J. G. Tait, T. Merckx, W. Qiu, U. W. Paetzold, L. Kootstra, M. Jaysankar, R. Gehlhaar, D. Cheyns, P. Heremans, J. Poortmans, Adv. Energy Mater. 2016, 6, 1600386.

[32] R. K. Henderson, C. Jimenez-Gonzalez, D. J. C. Constable, S. R. Alston, G. G. A. Inglis, G. Fisher, J. Sherwood, S. P. Binks, A. D. Curzons, Green Chem. 2011, 13, 854.

[33] M. Remeika, L. K. Ono, M. Maeda, Z. Hu, Y. Qi, Org. Electron. 2018, $54,72$.

[34] E. Ugur, A. D. Sheikh, R. Munir, J. I. Khan, D. Barrit, A. Amassian, F. Laquai, ACS Energy Lett. 2017, 2, 1960.

[35] R. Abbel, I. de Vries, A. Langen, G. Kirchner, H. t'Mannetje, H. Gorter, J. Wilson, P. Groen, J. Mater. Res. 2017, 32, 2219.

[36] Y. Zhou, O. S. Game, S. Pang, N. P. Padture, J. Phys. Chem. Lett. 2015, 6, 4827

[37] L. Yahui, Z. Zhenhao, L. Feng, C. Xiaobing, C. Xian, W. Jinquan, Small 2017, 13, 1604125.

[38] W. Nie, H. Tsai, R. Asadpour, J.-C. Blancon, A. J. Neukirch, G. Gupta, J. J. Crochet, M. Chhowalla, S. Tretiak, M. A. Alam, H.-L. Wang, A. D. Mohite, Science 2015, 347, 522.

[39] T. Matsui, J.-Y. Seo, M. Saliba, S. M. Zakeeruddin, M. Grätzel, Adv. Mater. 2017, 29, 1606258.

[40] C. Yi, J. Luo, S. Meloni, A. Boziki, N. Ashari-Astani, C. Gratzel, S. M. Zakeeruddin, U. Rothlisberger, M. Gratzel, Energy Environ. Sci. 2016, 9, 656.

[41] W. Rehman, D. P. McMeekin, J. B. Patel, R. L. Milot, M. B. Johnston, H. J. Snaith, L. M. Herz, Energy Environ. Sci. 2017, 10, 361.

[42] G. E. Eperon, T. Leijtens, K. A. Bush, R. Prasanna, T. Green, J. T.-W. Wang, D. P. McMeekin, G. Volonakis, R. L. Milot, R. May, A. Palmstrom, D. J. Slotcavage, R. A. Belisle, J. B. Patel, E. S. Parrott, R. J. Sutton, W. Ma, F. Moghadam, B. Conings, A. Babayigit, H.-G. Boyen, S. Bent, F. Giustino, L. M. Herz, M. B. Johnston, M. D. McGehee, H. J. Snaith, Science 2016, 354, 861.

[43] A. E. Williams, P. J. Holliman, M. J. Carnie, M. L. Davies, D. A. Worsley, T. M. Watson, J. Mater. Chem. A 2014, 2, 19338. 